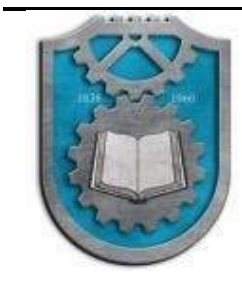

MOBILITY \& VEHICLE

MECHANICS

DOI: $10.24874 / \mathrm{mvm} .2021 .47 .04 .02$

UDC: 62592.3

\title{
A CONTRIBUTION TO THE DEVELOPMENT OF AUTOMOTIVE MAGNETORHEOLOGICAL BRAKE
}

Aleksandar Poznic ${ }^{1 *}$, Boris Stojic ${ }^{2}$

Received in July 2020

Revised in August 2020

Accepted in September 2020

RESEARCH ARTICLE

\begin{abstract}
The main challenges in automotive brake design are maintenance, response time, and braking torque. This paper is a part of the ongoing research that deals with the feasibility of incorporating magnetorheological type brake into the automotive size wheel. Materials, whose rheological properties change reversibly under the influence of an external force, belong to a group called smart materials. This group includes fluids, greases, gels, polymers etc. Materials whose rheological properties change under the influence of an external magnetic field are called magnetorheological materials. Magnetorheological grease is a type of material whose rheological properties also change due to an external magnetic field influence. The main disadvantages of any magnetorheological system are insufficient torque and/or settling effect. Increasing the magnetorheological brake`s braking torque by varying the shape and the number of active surfaces in contact with magnetorheological material is the basis of this research. Research partially relies on the results gained from earlier magnetorheological brake model simulations, done in COMSOL Multiphysics. Dealing with the magnetorheological material's settling effect, with the usage of magnetorheological greases, has been presented. Magnetic flux distribution analysis was carried out in a number of simulations, using the same software. The proposed design shows great potential.
\end{abstract}

KEY WORDS: brake, magnetorheological grease, settling, finite element method, magnetic flux distribution

(C) 2021 Published by University of Kragujevac, Faculty of Engineering

${ }^{I}$ Aleksandar Poznić, Assistant with PhD, University of Novi Sad, Faculty of Technical Sciences, Trg Dositeja Obradovića 6, 21000 Novi Sad, alpoznic@uns.ac.rs (*Corresponding author)

${ }^{2}$ Boris Stojić, Assist. prof., University of Novi Sad, Faculty of Technical Sciences, Trg Dositeja Obradovića 6, 21000 Novi Sad, bstojic@uns.ac.rs 


\section{DOPRINOS RAZVOJU AUTOMOBILSKE MAGNETNO-REOLOŠKE KOČNICE}

REZIME: Glavni izazovi u dizajnu automobilskih kočnica su održavanje, vreme odziva i kočni moment. Ovaj rad je deo tekućeg istraživanja koje se bavi mogućnostima izvođenja ugradnje magnetno-reološke kočnice veličine točka u automobile Materijali, čija se reološka svojstva reverzibilno menjaju pod uticajem spoljne sile, pripadaju grupi pametnih materijala. U ovu grupu spadaju tečnosti, masti, gelovi, polimeri itd. Materijali čija se reološka svojstva menjaju pod uticajem spoljašnjeg magnetnog polja nazivaju se magnetnoreološki materijali. Magnetno-reološka mast je vrsta materijala čija se reološka svojstva takođe menjaju usled uticaja spoljašnjeg magnetnog polja. Glavni nedostaci bilo kog magnetno-reološkog sistema su nedovoljan obrtni moment i/ili efekat taloženja. Povećanje kočonog momenta magnetno-reološke kočnice promenom oblika i broja aktivnih površina $u$ dodiru sa magnetno-reološkim materijalom osnova je ovog istraživanja. Istraživanje se delimično oslanja na rezultate dobijene ranijim simulacijama magnetno-reološkog modela kočnica, urađenim u COMSOL Multiphysics. Prikazana je analiza efekta taloženja magnetno-reološkog materijala primenom magnetno-reoloških masti. Analiza raspodele magnetnog toka izvedena je u brojnim simulacijama, primenom istog programskog paketa. Predloženi dizajn pokazuje veliki potencijal.

KLJUČNE REČI: kočnica, magnetno-reološka mast, taloženje, metoda konačnih elemenata, raspodela magnetnog fluksa 


\title{
A CONTRIBUTION TO THE DEVELOPMENT OF AUTOMOTIVE MAGNETORHEOLOGICAL BRAKE
}

\author{
Aleksandar Poznić, Boris Stojić
}

\section{INTRODUCTION}

In the last two decades, magnetorheological - MR materials and devices have gained great attention from researchers mainly because of their controllable properties and potential applications in various fields such as the automotive industry, the civil engineering, and the military sector [1]. Magnetorheological brake - MRB is a type of electromechanical brake that is comprised of a stator, rotor, working medium, and one or more excitation coils. Magnetorheological fluids - MRFs or magnetorheological greases - MRGs, are examples of working mediums that are commonly $[1,2]$ used in MRB design. The working medium of the MRB is contained between the stator and the rotor. The coils, when excited by the control current, generate magnetic fields that are each directed toward MR working medium through MRB`s body. Affected by the magnetic field, the MR medium`s viscosity changes [1-4]. Change in viscosity leads to a shift in rotational resistance between MRB`s stator and rotor thus increase in the overall braking torque value. Typical MRB is composed of magnetic and nonmagnetic materials. MR working medium is a magnetic material. Its magnetic properties can easily be obtained from its manufacturers. Nonmagnetic materials, such as aluminum, have known magnetic properties. On the other hand, magnetic properties of material such as construction steel, usually are not known or are not freely available, and need to be determined by measurements, [5]. The most important material's magnetic property, in this case, is the highly nonlinear initial magnetization curve, [5]. The major issues with any MRB`s application are viscosity level, solid-phase settling, and the overall braking torque value. There are several ways to overcome these issues. The first step is to use high viscosity, low setting rate MR working medium. Secondly, if possible, to further reduce $M R$ working medium gap size inside the device and to increase the applied magnetic flux acting on the MR working medium. The last one is to enhance the area of the active surfaces in contact with the MR working medium by increasing their heights and by multiplying their number.

The objective of this work was to simulate magnetic flux distribution through MRG layers of an innovative MRB type. MRG layers are constant in gap size - thickness but vary in heights. Particular magnetic flux distribution influence on each MRG layer was analyzed using a commercial Finite Element Method - FEM software. Simplification of the MRB FEM Model and the uniform magnetic flux distribution throughout all MRG layers were primal goals of the simulation. Obtained magnetic flux values were converted into braking torque values, using a predetermine mathematical model, for each layer.

\section{MAGNETORHEOLOGICAL BRAKE DESIGN}

The authors of this paper have used a hybrid MRB design. It combines known [6] Drum and $\mathrm{T}$-shape rotor brake type design. The new design relies on variations on each of the two types.

\subsection{Innovative design}

Illustrations in Figures 1 a)-c) are of new MRB design, its cross-section with emphasis on the MRG layers, and segment the multi-T-rotor assembly, respectively. Presented MRB is a design variation of the Drum and the T-shape rotor design. Opposed to the Drum brake type, 
that only has one coil, or to the T-shaped rotor brake, that has two separate coils, this design has eight individual stationary coils, thus forming a multi-pole structure. These eight excitation coils are divided into two groups. The first coil group is radially arranged on the circumference of an MRB`s stator. The second group, the parallel coils, is positioned parallel to the rotor's shaft axis, Figure 1, a) and partially b). Each radial coil's magnetic flux vector is directed towards the center of the MRB, for combined effect increase in the overall magnetic flux intensity $-\vec{B}$, acting on the MRG layers equidistantly arranged inside the brake. Both parallel coil's $\vec{B}$ are directed opposite to each other i.e. outwards, away from the center of the MRB.

To increase the total MRG active surface area, the T-rotor element was concentrically multiplied several times inwards, thus forming a multi-T-rotor element, Figure $1 \mathrm{c}$ ). The proposed MRB multi-T-rotor assembly, i.e. shaft and multi-T element, is composed of both nonmagnetic and magnetic materials. The nonmagnetic shaft also features a nonmagnetic disk, designated as multi-T-element inner support. To have a closed magnetic circuit, two six-spoke magnetic flux return bridges were added, Figure 1, a) and partially b). The magnetic flux spreading pattern is illustrated latter in text in Figure 5.

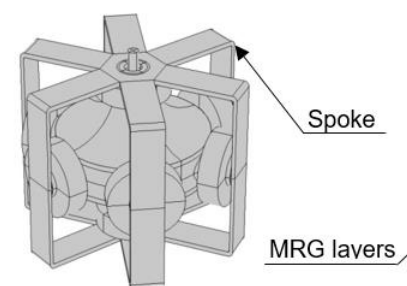

a)

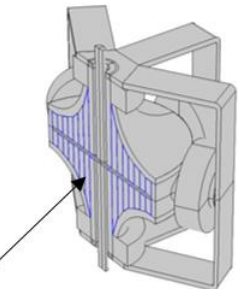

b)

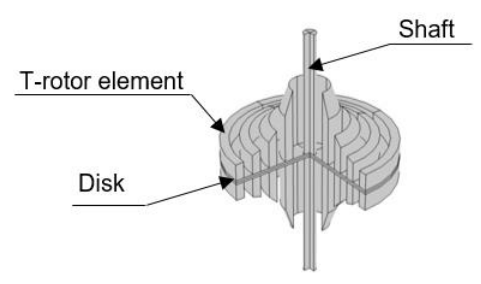

c)

Figure 1 Magnetorheological multi-pole multi-T-rotor brake model, a) innovative design,

b) cross-section of the model with an emphasis on active surfaces, c) segmental representation of the multi-T-rotor assembly

\subsection{Material properties}

The main property of ferromagnetic materials is their magnetic hysteresis loop or initial magnetization curve [5]. This phenomenon is illustrated in Figure 2 a) and b). Ferromagnetic materials, with small hysteresis loop area - magnetically soft materials, are suitable for electromagnets production. On the other hand materials with large hysteresis loop area - magnetically hard materials, are better suited for permanent magnets production, Figure 2 a). Rule of the thumb is that body of the MRB should be made of magnetically soft steel, because of the residual magnetic induction influence. 


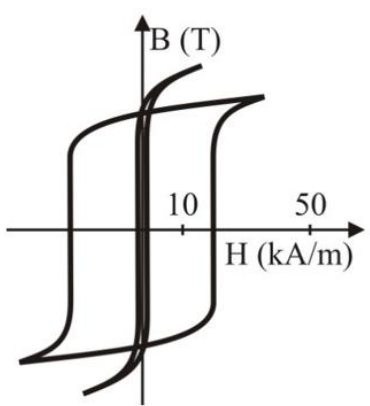

a)

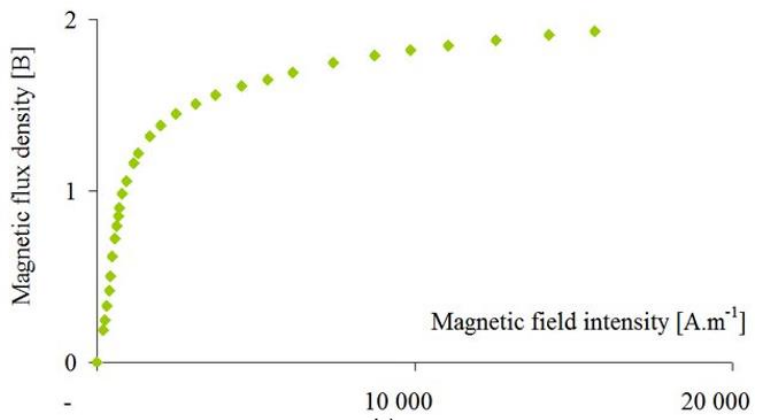

b)

Figure 2 a) Hysteresis loops of magnetically soft steel (small hysteresis loop area) and magnetically hard steel (large hysteresis loop area) [5], b) AISI 1018 B-H curve [8]

To be able to analytically determine the MRB output torque range, one needs to know the magnetic properties of both the construction steel and MRG in use. As mentioned earlier, the magnetic characteristics of all ferromagnetic materials are not regularly available, so the Authors decided for AISI 1018 steel with known magnetic characteristics. The magnetic field versus magnetic flux density relationship of AISI 1018 is presented in Figure $2 \mathrm{~b}$ ). The main problem with liquid-based MR working medium is the so-called solid phase settling. This phenomenon leads to the reduction of the MR effect and limits the long-lasting usability of the MRF as a working medium. This is especially important in applications such as automotive brakes/clutches because it can lead to device improper operation. The settling occurs due to the mismatch of densities of the liquid base MRF and its CI particle. Compared to the MRF, the unique behavior of MRG is that it does not allow a flow of the magnetic CI particles without the presence of external force, (performs as non-Newtonian fluids at both off-state and on-state conditions), [2]. Based on this, it can be presumed that the grease is better suited for MR devices applications, best of all to eliminate the settling problem. The soft magnetic carbonyl iron - CI particle weight fraction in MRG has a significant impact on its magnetic properties. The larger this percentage is, the higher the magnetization is. Based on this, an MRG with $70 \mathrm{wt} \%$ soft magnetic CI particle concentration [3] was selected as a working medium in this FEM simulation. Another problem, that occurs in exploitation conditions, is MR device leakage. The high viscosity of synthetic or mineral oil in MRF requires appropriate sealing to inhibit device leakage, and may indirectly lead to device failure or degradation of its performances. On the other hand, it should be mentioned that the greases are known to have self-sealing properties, to be robust at extreme temperatures and pressures, and have anti-wear properties as well as friction reduction properties in a lubrication role.

\section{NUMERICAL SIMULATIONS}

The proposed MRB design was modeled using commercial FEM software, COMSOL Multiphysics [7]. Due to the presence of the nonmagnetic disk and two six-spoke magnetic flux density return bridges, Figure 1 a), COMSOL`s 3D space dimension option was utilized. The magnetic field was considered to be static, so the Stationary Study was used. To reduce the required computation power the Model was simplified to a twelfth the volume of the original Model, Figure 3 a). The entire model was surrounded by a sphere-shaped air boundary, several times the volume of the Model. Appropriate material nodes and boundary conditions were assigned to every element of the Model. In this specific simulation, 
materials such as nonmagnetic air and aluminium were selected from COMSOL's database, but nonlinear magnetic materials, such as AISI 1018 steel and MRG with 70 wt. \%, were manually defined. These data have been loaded to the COMSOL as separate files. Note, presence of elements such as ball bearings were neglected because of their steel composition and small volume share in the overall construction. In the Magnetic Fields subsection of the model, additional Ampère's Laws were needed, due to the use of several different materials. In the same subsection, only three Multi-Turn Coil domain nodes were added due to the axial symmetry cut implemented in this Model. Mesh, Figure $3 \mathrm{~b}$ ), was generated using the User-controlled mesh. The MRG's layers were meshed using the Free tetrahedral with custom element size. Also, special attention was placed on the curvatures and the narrow regions of MRG segments of the brake. The curvature radii were multiplied by the Curvature factor parameter which in return. gives the maximum allowed element size along a specific boundary. The Resolution of narrow regions parameter controls the number of elements created in narrow regions. These parameters greatly improved the mash quality of the models, which is now at the threshold of 0.1 , which is considered a satisfactory mesh. The solver was stationary but non-linear.

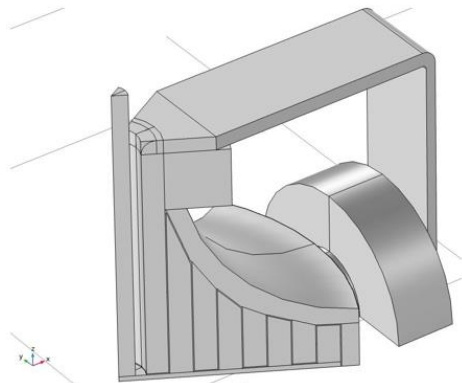

a)

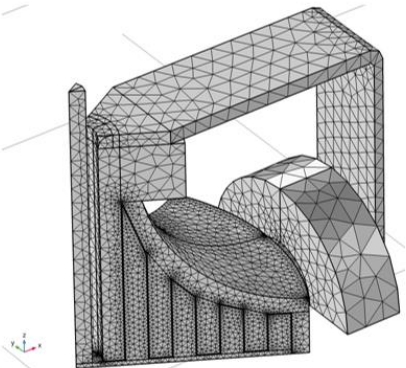

b)

Figure 3 Proposed magnetorheological multi-pole multi-T-rotor brake's a) simplified Model and b) Model's mesh

To determine the overall magnetic flux intensity in a specific MRG layer FEM simulation was carried out. A median magnetic flux value was determined along three predetermined circular lines for each MRG layer. Circular lines were positioned at the very top of every MRG layer, in the middle of it, and at the very bottom of it. Illustrations of these lines in the outer MRG layer are presented in Figures 4 a)-c). A 1D Plot Group line graph was used to depicture the magnetic flux magnitude changes along these three circular lines for each MRG layer.

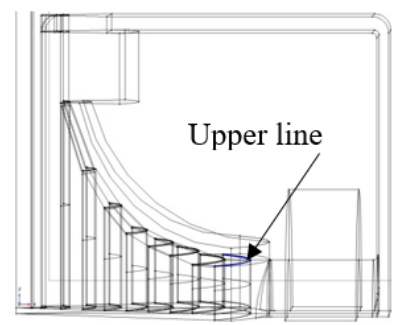

a)

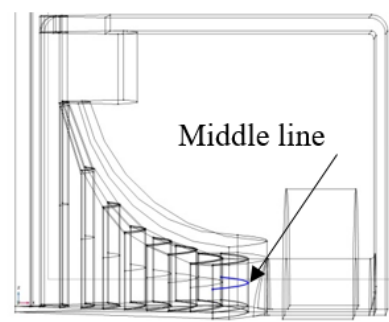

b)

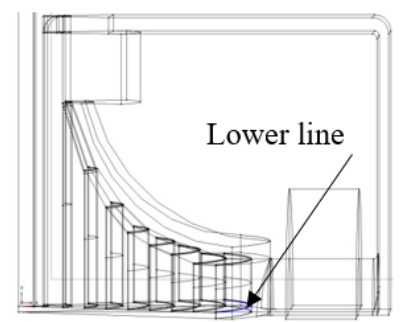

c)

Figure 4 Median magnetic flux value determined along three circular lines, a) Upper b) Middle and c) Lower line of the outer rim MRG layer 


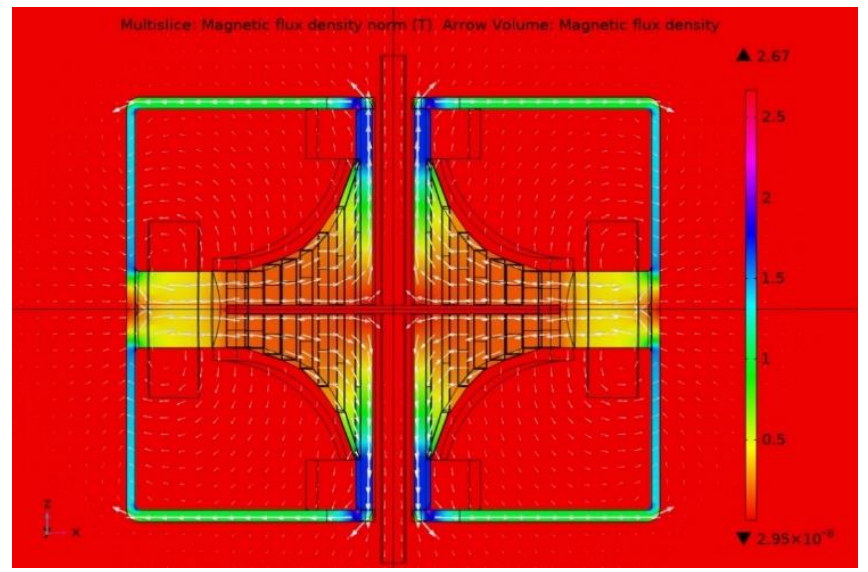

Figure 5 Magnetorheological brake cross-section with magnetic flux spreading routes illustration

Due to the MRB Model's simplification, only two Multi-Turn Coil domain nodes were needed, Figure 6 a). This greatly reduced the required computational power and simulation time. The continuous MRG layers were designed in such a manner that their active surfaces were always perpendicular, as much as possible, to the magnetic flux vector, Figures 5 and 6 b). The hexagonal prism stator, the coils' cores, the multi-T-rotor element, and the six-spoke magnetic flux return bridges, Figure $6 \mathrm{c}$ ), were assigned with the magnetically soft steel AISI 1018. The rest of the MRB assembly elements, Figure $6 \mathrm{~d}$ ), were assigned with nonmagnetic materials. One of these elements is the nonmagnetic disk. The nonmagnetic disk diverts magnetic flux lines spreading route through the body of the MRB, and splits it into two magnetic flux layers, Figure 5. These two layers act uniformly onto separate but geometrically equal segments of the MRG active surfaces. A brief parameter overview of the proposed MRB design is presented in Table 1. The proposed MRB model is planned to be manufactured in the near future. 


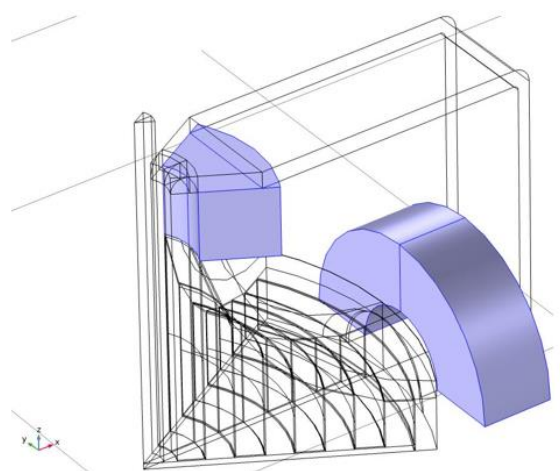

a)

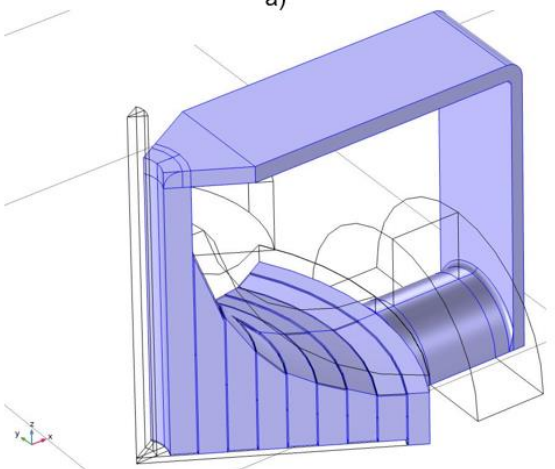

c)

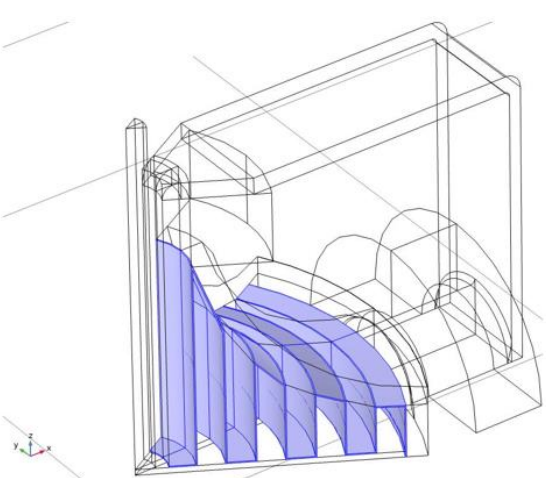

b)

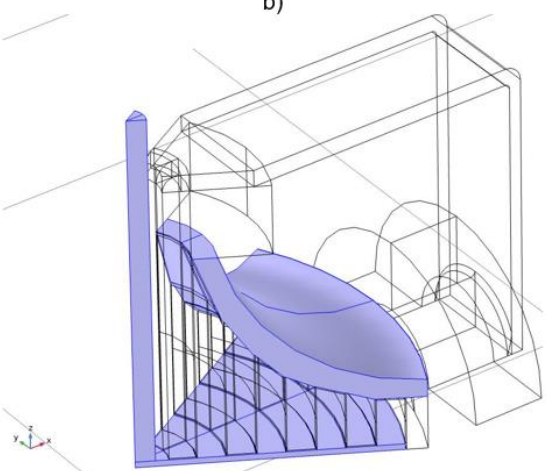

d)

Figure 6 Proposed magnetorheological multi-pole multi-T-rotor brake's elements crosssection illustrations, a) Colis b) MRG layers, c) core and d) nonmagnetic elements of the brake

Table 1 Multi-pole multi-T-rotor magnetorheological brake parameters

\begin{tabular}{|l|l|}
\hline Parameter & Value \\
\hline Magnetorheological brakes` outer diameter (mm) & 315 \\
\hline Magnetorheological brake`s length (shaft not included) (mm) & 127.45 \\
\hline Multi-T-element outer radius (mm) & 100 \\
\hline Magnetorheological fluid`s active area height; from - up to (mm) & $20.5-90.45$ \\
\hline Nonmagnetic disks' thickness (mm) & 2.5 \\
\hline Nonmagnetic disk radius (mm) & 100 \\
\hline Shafts' diameter (mm) & 15 \\
\hline Magnetorheological fluid gap (mm) & 0.5 \\
\hline Number of coils (-) & 8 \\
\hline Maximum control current intensity per coil (A) & 100 \\
\hline
\end{tabular}

\subsection{Numerical torque modeling}

In the case of the multi-T-rotor brake, the torque generating properties can be described by the same analytical model used for the MR drum brake model with the results adjustment for additional MRF layers and their specific radii and heights. The maximum field-induced torque, for MR drum brake, is given by: 


$$
T_{\tau}=\sum_{1}^{k} 2 \cdot R_{o_{k}} \cdot\left(2 \cdot \pi \cdot R_{o_{k}} \cdot I_{k}\right) \cdot \tau_{y}=\sum_{1}^{k} 4 \cdot \pi \cdot \tau_{y} \cdot\left(I_{k} \cdot R_{o_{k}}^{2}\right)
$$

Similarly, the maximum viscous torque is:

$$
T_{\eta}=\sum_{1}^{k} 4 \cdot \pi \cdot \eta \cdot \frac{\dot{\theta}}{g} \cdot\left(I_{k} \cdot R_{o_{k}}^{3}\right)
$$

where, $k$ is the number of MRF layers, $R_{o k}$ is a radius of a specific MRF layer, $l_{k}$ is the MRG layer`s height, $\tau_{y}$ is the yield stress developed in response to the applied magnetic field, $\eta$ is the viscosity of the MR fluid with no applied magnetic field, $\dot{\theta}$ is the angular velocity of the rotor and $g$ is the thickness of the MR fluid gap.

It was assumed that the overall intensity of the $\vec{B}$ will increases as it progresses toward inner MRF layers, because of the combining effect of all excitation coils. But the summarization of all excitation coils led to a noticeable decrease of the $\vec{B}$ with the decrease of the $R_{o_{k}}$. To exclude this effect, the researchers tried to fix the product of the $\left(I_{k} \cdot R_{o_{k}}^{2}\right)$ to a specific value. This value was determined at the very far radius and the very least height of the MRG layer. The only variable here was the height of the MRF. This has led to a distinctive curvature in T-rotor design, which was not entirely accepted due to manufacturing restrictions. This combination resulted in a different magnetic flux distribution i.e. equal overall torque contribution from each of the MRG layers. Magnetic flux intensity simulations results are presented in this paper.

\section{RESULTS AND DISCUSION}

\subsection{Magnetic flux density distribution}

The magnetic flux distribution pattern within the proposed MRB was studied and the results were presented. The average magnetic flux intensity change in each MRG layer compared to layer's heights is presented in Figure 7. Here a monotonically declining linearity in magnetic flux change through MRG layers is noticeable. This suggests the inconsistency in the field-induced torque values through MRG layers. In Figure 8 a sample of the actual magnetic flux intensity simulation results, generated by a single radial coil, is depicted. The average numerical values for magnetic flux intensity are given in Table 2. These values were determined along three circular lines for each MRG layer. Excellent results repeatability along these lines were achieved. Some inconsistencies in magnetic flux distribution results were present though. The reasons for this lies in the fact that the excitation coils had a radial, periodical arrangement and the MRG layers had a specific shape with progressive heights. But the main reason for the discrepancies between specific layer's three-line results was their closeness to the MRG/nonmagnetic material boundaries. This led to significant drop in results value for the lower and the upper line compared to the middle line.

Table 2 Numerical values of magnetic flux intensities at specific radii 


\begin{tabular}{|c|c|c|}
\hline \multicolumn{3}{|c|}{ Improved magnetorheological brake design } \\
\hline Layer & $\mathrm{B},[\mathrm{T}]$ & $R_{o_{k},[\mathrm{~mm}]}$ \\
\hline 1 & 0.0570 & 22.75 \\
\hline 2 & 0.0545 & 33.82 \\
\hline 3 & 0.0520 & 44.89 \\
\hline 4 & 0.0510 & 55.96 \\
\hline 5 & 0.0500 & 67.03 \\
\hline 6 & 0.0490 & 78.10 \\
\hline 7 & 0.0475 & 89.17 \\
\hline 8 & 0.0450 & 100.25 \\
\hline
\end{tabular}

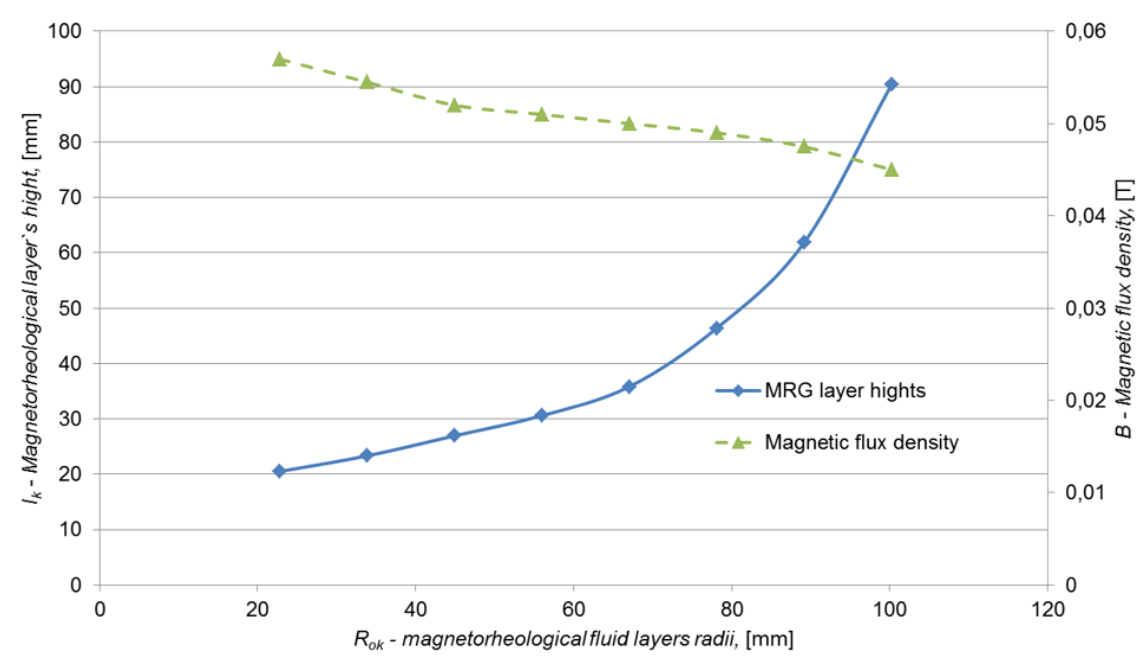

Figure 7 Changes in MRG layer's heights compared to changes in magnetic flux intensity in each MRG layer 


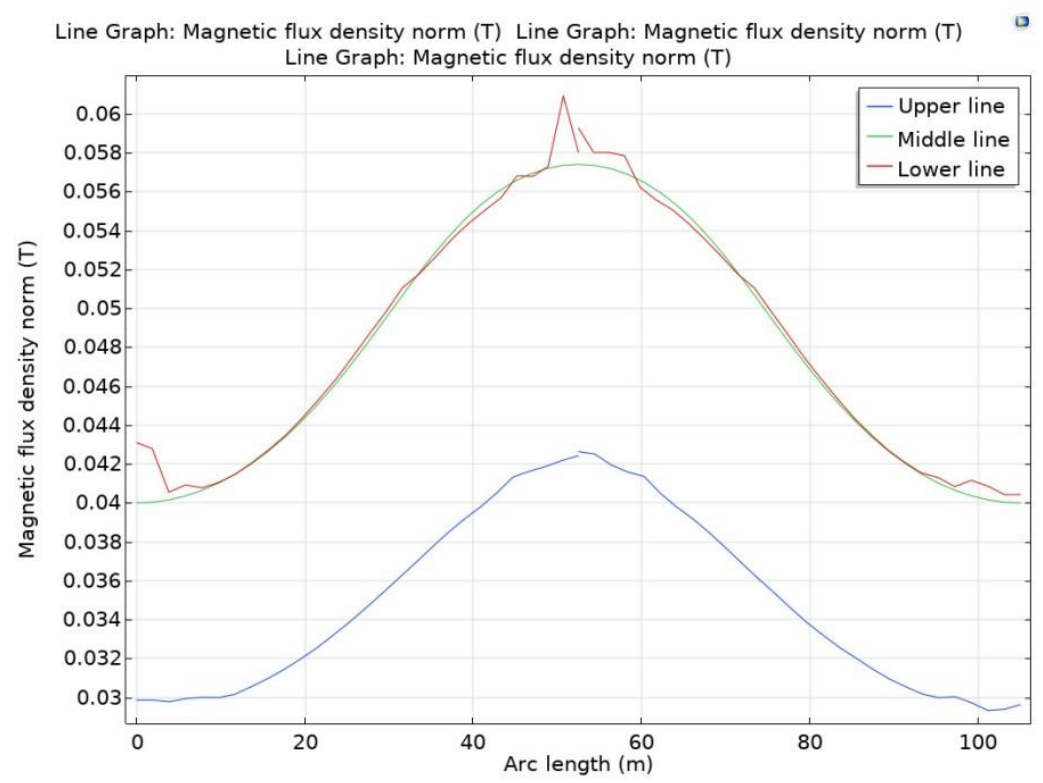

Figure 8 A sample of the magnetic flux simulation results for magnetorheological multipole multi-T-rotor brake

\section{CONCLUSIONS}

This study presented a novel standpoint on magnetorheological brakes design. An improved magnetorheological brake design was introduced. By combining magnetic and nonmagnetic materials, a new space may have been opened for magnetorheological technology. The use of non-magnetic material and a specific shape of inner elements lead to magnetic flux unique distribution through MRG layers and MRB's body. The goal of the study was to determine magnetic flux intensity change taking into account the heights of MRG's layers as well. For this purpose, the MRB finite element Model was made using commercial finite element type software. To reduce the required computation power the Model was simplified to a twelfth the volume of the real Model. The Model had the same basic geometry and excitation coils properties. Magnetic flux intensities along specific lines inside magnetorheological grease layers were obtained. Results are presented graphically and tabularly.

A nonlinear relationship between magnetic flux and magnetic field in different materials was applied in the simulations. A combination of materials shapes may contribute to other magnetorheological applications, where there is a need for magnetic flux increase in small areas, but where geometric restrictions are present. It was concluded that the overall magnetic flux density inside MRB decreases with a decrease of the multi-T-rotor radius. This is not favorable in terms of overall torque generation. Further analysis led to the conclusion that the induced torques in MRG layers was not equal and not contributing equally to the overall torque value, thus stressing unfavorably the entire MRB construction. 
The proposed multi-pole multi-T-rotor MRB design shows great potential but needs further geometry improvements. Greater braking torque, in constrained volume and weight, is now achievable. Future work should be focused on equalization of the magnetic flux density through magnetorheological grease`s layers which were not the case in this study. This is a part of ongoing MRB Model topology optimization.

\section{ACKNOWLEDGMENTS}

This research (paper) has been supported by the Ministry of Education, Science and Technological Development through the project no. 451-03-68/2020-14/200156: "Innovative scientific and artistic research from the FTS (activity) domain".

\section{REFERENCES}

[1] Raju, A., Choi, S., Ferdaus, M.: "A state of art on magneto-rheological materials and their potential applications", Journal of Intelligent Material Systems and Structures, 2018, Vol 29, No. 10, pp. 2051-2095. Doi: 10.1177/1045389X18754350.

[2] Mohamad, N., Mazlan, S. A., Ubaidillah, Choi S. Nordin. M.F.M.: "The fielddependent rheological properties of magnetorheological grease based on carbonyliron-particles", Smart Materials and Structures, 2016, Vol. 25, No. 9, pp. 1-10.

[3] Karakoc, K., Park, E. J., Suleman, A.: "Design considerations for an automotive magnetorheological brake", Mechatronics, Vol. 18, No. 8, pp. 434 - 447. Doi: 10.1016/j.mechatronics.2008.02.003.

[4] Poznić, A., Stojić, B.: "A contribution to the analysis of magnetorheological brake", The 10th International Symposium Machine and Industrial Design in Mechanical Engineering (KOD 2018), 2018, Vol. 10, pp. 1 - 9.

[5] Poznić, A., Miloradović, D., Zelić, A.: "Determination of magnetic characteristics of some steels suitable for magnetorheological brake construction", 3rd International Conference and Workshop Mechatronics in Practice and Education - MECHEDU 2015, 14th-16th May 2015, pp. 130-133.

[6] Avraam, M. T.: "MR-fluid brake design and its application to a portable muscular rehabilitation device", $\mathrm{PhD}$ thesis, Active Structures Laboratory Department of Mechanical Engineering and Robotics, 2009, Bruxelles.

[7] Comsol Multiphysics, AC/DC Module, User's Guide. https://www.comsol.com/.

[8] Roupec, J., Kubik, M., Mazurek, I., Strecker, Z.: "Problems of FEM analysis of magnetic circuit”, In: Březina, T., Jabloński, R. (eds) Mechatronics, 2013, pp. 299 305 . 